\title{
ESTUDO DA SECAGEM SOLAR DE LODO PROVENIENTE DE BIODIGESTÃO ANAERÓBIA
}

\author{
A. SCALCON ${ }^{1 *}$, M. L. GIMENES ${ }^{1}$, C. F. M. MOREJÓN ${ }^{2}$, G. JOHANN ${ }^{1}$, J. R. MELO ${ }^{1}$ A. P. \\ SONE $^{1}$ \\ ${ }^{1}$ Universidade Estadual de Maringá, Departamento de Engenharia Química \\ ${ }^{2}$ Universidade Estadual do Oeste do Paraná, Centro de Engenharias e Ciências Exatas \\ *e-mail: araceliscalcon@gmail.com
}

\begin{abstract}
RESUMO
O lodo digerido, remanescente de processos de biodigestão possui grande potencial de uso como fertilizante. Porém, para garantir a sua qualidade é necessária, entre outras etapas, a desidratação/secagem do mesmo. Uma alternativa eficaz e barata é a utilização da secagem solar. Nesse contexto o objetivo deste trabalho foi analisar a influência de fatores relevantes na secagem solar do lodo. Foi realizado um planejamento experimental do tipo fatorial completo $2^{3}$ com triplicata no ponto central, onde foram avaliados os efeitos das variáveis: superfície de secagem, velocidade do ar de secagem e agitação sobre o tempo de secagem. Os resultados obtidos mostraram um alto teor de umidade inicial do lodo confirmando a necessidade de uma etapa de secagem. Os resultados do planejamento experimental mostraram que as três variáveis interferiram significativamente no tempo de secagem, inclusive a interação entre a velocidade do ar e área de secagem. O efeito principal foi atribuído à velocidade do ar, seguido da superfície de secagem e da agitação. A cinética de secagem foi ajustada por modelos matemáticos (Lewis, 1921; Henderson-Pabis, 1961; Henderson, 1974 e Logarítmico) e estes apresentaram um bom ajuste aos dados experimentais, permitindo prever $\mathrm{o}$ comportamento do lodo durante a secagem.
\end{abstract}

\section{INTRODUÇÃO}

O aumento populacional e a crescente industrialização são fatores que promovem agravamento na geração de resíduos, os quais, mesmo após o tratamento, ainda apresentam grande potencial de poluição e contaminação do solo, da água (superficial e subterrânea) e do ar (FILHO, 1999).

Considerando a maior porcentagem de resíduos orgânicos na composição do lixo, diversos autores (DE BAERE, 2000; BOUALAGUI et al., 2004; MOREJON et al., 2012) apontam a digestão ou fermentação anaeróbia da fração orgânica de resíduos sólidos urbanos, principalmente resíduos alimentares, como uma alternativa atraente e rentável. Além da produção de biogás, utilizado como fonte de geração de energia térmica, mecânica e/ou elétrica, o processo possibilita a reciclagem da biomassa, tendo como base o aproveitamento do lodo como fertilizante.

Entretanto, para o efetivo aproveitamento do lodo como fertilizante, principalmente para garantir a sua qualidade, é necessário o atendimento de algumas exigências do mercado, entre elas as características físicas e químicas compatíveis com o solo, sua forma de apresentação, de preferência no estado sólido e seco, bem como garantir a inexistência de organismos patogênicos e/ou de constituintes tóxicos. 
Para viabilizar com segurança o uso do lodo proveniente da biodigestão como fertilizante agrícola, este deve passar, entre outras etapas, por um processo de desidratação/secagem. Além disso, com a diminuição do peso e volume do lodo, ocorre também a diminuição dos custos de transporte e disposição.

Considerando também a possibilidade da presença de micro-organismos patogênicos e a necessidade da diminuição de custos energéticos a desidratação/secagem utilizando a energia solar mostra-se uma alternativa eficaz para o tratamento do lodo, pois além de retirar a água, também contribui para a diminuição da atividade microbiológica devido ao poder germicida dos raios ultravioleta presentes na radiação solar.

\subsection{Fundamentos da Secagem}

$\mathrm{O}$ termo secagem refere-se à transferência da umidade presente num sólido para uma fase gasosa não saturada (FOUST et al., 1982).

Segundo Deng et al. (2009) e Vaxelaire \& Cézac (2004), o comportamento geral do lodo durante o processo de secagem, sob condições operacionais constantes, é dividido em quatro partes principais. Esse comportamento é típico para maioria dos processos de secagem e é ilustrado na Figura 1.

O primeiro momento é muito curto e, por essa razão, não é mostrado na Figura 1. Trata-se da adaptação do lodo às condições operacionais. Após a estabilização das condições operacionais, a taxa de secagem é constante, como mostrado no período AB. A secagem ocorre como se fosse a evaporação de uma massa de líquido, sem haver influência direta do sólido na taxa de secagem. A temperatura da superfície atinge a temperatura de bulbo úmido (McCABE et al., 1993).

Quando o sólido atinge a umidade crítica $\left(X_{C}\right)$, se inicia o primeiro período de secagem a taxa decrescente, período BC. A superfície fica gradativamente mais pobre em líquido, pois a velocidade do movimento do líquido para a superfície é menor que a velocidade com que a massa é transferida da superfície (McCABE et al., 1993).

$\mathrm{O}$ próximo período, $\mathrm{CD}$, também apresenta uma taxa de secagem decrescente. O último período de curva é um curto intervalo de tempo, em que a água ligada é removida e a umidade de equilíbrio é atingida $\left(X_{\text {eq }}\right)$ (McCABE et al., 1993).

Figura 1 - Taxas de secagem do lodo

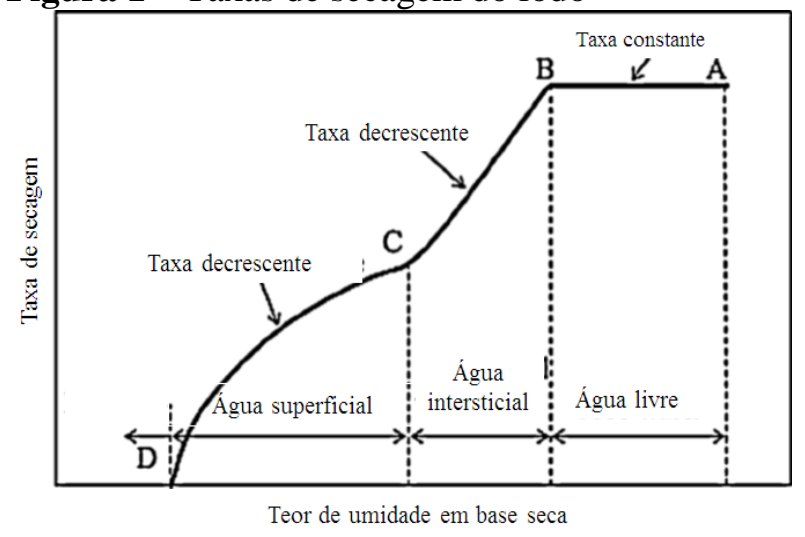

Fonte: BENNAMOUN (2012).

O teor de umidade médio em base seca em cada ponto pode ser calculado pela Equação 1, em que $m_{i}$ é a massa inicial da amostra e m é a massa da amostra em cada ponto de monitoramento.

$$
\bar{X}=\frac{m_{i}-m}{m}
$$

Segundo McCabe et al. (1993), para estudar a operação de secagem, pode-se obter a curva que relaciona a variação adimensional de umidade $X_{R}$ (que pode ser calculada pela Equação 2) em função do tempo, em que $X_{0}$ é o teor de umidade inicial.

$$
X_{R}=\frac{\overline{\bar{X}}-X_{e q}}{X_{0}-X_{e q}}
$$


A taxa de secagem mede a razão entra a variação do teor de umidade $(\Delta \mathrm{X})$ e a variação de tempo $(\Delta \mathrm{t})$ e pode ser calculada pela Equação 3.

$$
N=-\frac{m_{s}}{A} \frac{\Delta X}{\Delta t}
$$

Nesse contexto, o objetivo deste trabalho foi analisar a influência de fatores relevantes na secagem solar do lodo.

\section{MATERIAIS E MÉTODOS}

O lodo utilizado foi o lodo biodigerido proveniente de um sistema de biodigestão desenvolvido na Universidade Estadual do Oeste do Paraná - Campus Toledo, por LAUFER (2008).

\subsection{Caracterização do teor de umidade do lodo}

A determinação do teor de umidade foi realizadas pelo método proposto por Kiehl (1985).

\subsection{Tratamento dos dados experimentais e modelagem}

Foi analisada a influência de três variáveis independentes na secagem solar de lodo: velocidade do ar, superfície de secagem e agitação da amostra. Para tanto, optou-se por um planejamento fatorial completo $2^{3}$ com triplicata no ponto central, resultando em 11 ensaios.

As variáveis são: velocidade do ar $(0$ $\mathrm{m} / \mathrm{s}, 2$ a $2,5 \mathrm{~m} / \mathrm{s}$ e 4 a $4,5 \mathrm{~m} / \mathrm{s})$, superfície de secagem das bandejas $\left(77 \mathrm{~cm}^{2}, 160 \mathrm{~cm}^{2}\right.$ e $240 \mathrm{~cm}^{2}$ ) e agitação (sem agitação, 2 agitações por hora - intervalos de 30 minutos e com 4 agitações por hora - intervalos de 15 minutos). A Tabela 1 mostra o planejamento experimental realizado. A variável resposta foi o tempo residência das amostras para atingir a umidade de equilíbrio.
Os resultados foram analisados com o auxílio do programa Statistica, versão 8.0 (STATISTICA, 2008).

Este procedimento de secagem ocorreu no verão em dias ensolarados, com ventos fracos a moderados. De acordo com o planejamento experimental, foram feitos 11 ensaios. As amostras foram colocadas em recipientes de plásticos com 3 tamanhos diferentes para avaliar a influência da superfície de secagem. Os diferentes valores de velocidade do ar foram obtidos por meio de ventiladores. A agitação foi realizada por meio de uma espátula.

Tabela 1 - Planejamento fatorial completo $2^{3} \mathrm{com}$ triplicata no ponto central.

\begin{tabular}{|c|c|c|c|}
\hline \multirow[t]{2}{*}{ Ensaios } & $\begin{array}{l}\text { Variáveis } \\
\text { codificados }\end{array}$ & em & níveis \\
\hline & $\mathrm{X}_{1}$ & $X_{2}$ & $\mathrm{X}_{3}$ \\
\hline 1 & - & - & - \\
\hline 2 & + & - & - \\
\hline 3 & - & + & - \\
\hline 4 & + & + & - \\
\hline 5 & - & - & + \\
\hline 6 & + & - & + \\
\hline 7 & - & + & + \\
\hline 8 & + & + & + \\
\hline 9 & 0 & 0 & 0 \\
\hline 10 & 0 & 0 & 0 \\
\hline \multirow[t]{6}{*}{11} & 0 & 0 & 0 \\
\hline & \multicolumn{3}{|c|}{ Níveis reais } \\
\hline & +1 & 0 & -1 \\
\hline & $4-4,5$ & $2-2,5$ & 0 \\
\hline & 240 & 160 & 77 \\
\hline & 4 & 2 & 0 \\
\hline
\end{tabular}

Fonte: Autor.

Devido ao alto teor de umidade inicial do lodo, foi adaptado nos recipientes um sistema de filtração por meio poroso, para que ocorressem simultaneamente as operações de filtração e secagem, aumentando a eficiência do processo.

Modelos matemáticos descritos com base na teoria da difusão são uma alternativa 
para descrever a cinética de secagem. $\mathrm{Na}$ Tabela 2 são mostrados os modelos utilizados neste estudo.

Tabela 2 - Modelos de cinética de secagem

\begin{tabular}{cl}
\hline Equação & Modelo \\
\hline $\boldsymbol{X}_{\boldsymbol{R}}=\boldsymbol{e}^{(-\boldsymbol{k} . t)}$ & Lewis (1921) \\
$\quad \boldsymbol{X}_{\boldsymbol{R}}=\boldsymbol{a} \cdot \boldsymbol{e}^{(-\boldsymbol{k} . t)}$ & Henderson-Pabis (1961) \\
$\boldsymbol{X}_{\boldsymbol{R}}=\boldsymbol{a} \cdot \boldsymbol{e}^{\left(-\boldsymbol{k}_{1} \cdot t\right)}+\boldsymbol{b} \cdot \boldsymbol{e}^{\left(-\boldsymbol{k}_{1} \cdot t\right)}$ & Henderson (1974) \\
$\boldsymbol{X}_{\boldsymbol{R}}=\boldsymbol{a} \cdot \boldsymbol{e}^{\left(-\boldsymbol{k}_{1} \cdot \boldsymbol{t}\right)}+\boldsymbol{c}$ & Logaritmico \\
\hline
\end{tabular}

\section{RESULTADOS}

\subsection{Caracterização do teor de umidade do lodo}

O teor de umidade inicial encontrado foi de 95,6\%. Este alto valor está se acordo com os valores encontrados por Andreoli et al. (2000).

\subsection{Tratamento dos dados experimentais e modelagem}

Os resultados do planejamento experimental encontram-se na Tabela 3. As considerações estatísticas, obtidas com a análise dos dados relativa aos resultados do experimento estabeleceram os critérios para definir os fatores experimentais analisados (velocidade do ar, superfície de secagem e agitação), que tiveram efeito significativo, a um nível de confiança de 95\% ( $\mathrm{p}<0,05$ ), sobre a variável resposta desejada, ou seja, sobre o tempo de secagem. Na Tabela 3 podem ser observados os 11 ensaios realizados, as variáveis em níveis reais e codificados e o tempo de secagem até a obtenção do teor de umidade de equilíbrio.

Analisando a Tabela 2 observa-se que a amostra 8 foi a primeira a atingir o equilíbrio, após 9 horas de secagem. Este resultado confirma que as condições mais favoráveis à secagem são aquelas com maior velocidade do ar, maior superfície de secagem e maior número de agitações, neste caso, $4 \mathrm{~m} / \mathrm{s}$, $240 \mathrm{~cm}^{2}$ e 4 agitações por hora, respectivamente.
Esta análise pode ser confirmada comparando-se as condições da amostra 8 às condições da amostra 1 (velocidade do ar de 0 $\mathrm{m} / \mathrm{s}$, área de superfície de $77 \mathrm{~cm}^{2}$ e nenhuma agitação), que eram extremas umas às outras. A amostra 1 foi a última a atingir o equilíbrio, após 21 horas de secagem.

Tabela 3. Resultados do experimento.

\begin{tabular}{|c|c|c|c|c|}
\hline \multirow[t]{2}{*}{ Ensaios } & \multicolumn{3}{|c|}{$\begin{array}{c}\text { Variáveis em } \\
\text { níveis codificados }\end{array}$} & \multirow[t]{2}{*}{$\begin{array}{c}\text { Resposta } \\
\mathrm{t}(\mathrm{h})\end{array}$} \\
\hline & $\mathrm{X}_{1}$ & $\mathrm{X}_{2}$ & $\mathrm{X}_{3}$ & \\
\hline 1 & - & - & - & 21 \\
\hline 2 & + & - & - & 19 \\
\hline 3 & - & + & - & 20 \\
\hline 4 & + & + & - & 11 \\
\hline 5 & - & - & + & 19 \\
\hline 6 & + & - & + & 17 \\
\hline 7 & - & + & + & 17 \\
\hline 8 & + & + & + & 9 \\
\hline 9 & 0 & 0 & 0 & 17 \\
\hline 10 & 0 & 0 & 0 & 17 \\
\hline \multirow[t]{6}{*}{11} & 0 & 0 & 0 & 17 \\
\hline & \multicolumn{3}{|c|}{ Níveis reais } & \\
\hline & +1 & 0 & -1 & \\
\hline & $4-4,5$ & $2-2,5$ & 0 & \\
\hline & 240 & 160 & 77 & \\
\hline & 4 & 2 & 0 & \\
\hline
\end{tabular}

Fonte: Autor.

As demais amostras apresentarem um tempo de secagem intermediário entre essas duas, com um tempo médio de 17 horas de secagem.

Na Tabela 4 são apresentados os resultados das estimativas dos efeitos para o tempo de secagem, onde pode-se observar os valores dos efeitos de cada variável estudada, assim como os coeficientes, seus respectivos erros-padrão e p-valor. Os valores considerados significativos ao nível de significância de $95 \%$ estão apresentados em negrito.

Os fatores significativos são aqueles que apresentam o p-valor menor que 0,05 . Os três fatores analisados, incluindo a interação entre dois deles (velocidade do ar e área de secagem) se mostraram significativos. O 
gráfico de Pareto, mostrado na Figura 2 evidencia este comportamento.

Tabela 4. Tabela de efeitos no tempo de secagem.

\begin{tabular}{lcrccc}
\hline & Efeito & $\begin{array}{c}\text { Erro } \\
\text { padrão }\end{array}$ & p-valor & $\begin{array}{c}\text { Coefici- } \\
\text { ente }\end{array}$ & $\begin{array}{c}\text { Erro } \\
\text { padrão }\end{array}$ \\
\hline I & $\mathbf{1 6 , 7 2 7 3}$ & $\mathbf{0 , 0 9 9 0 7}$ & $\mathbf{0 , 0 0 0 0 0 0}$ & $\mathbf{1 6 , 7 2 7 3}$ & $\mathbf{0 , 0 9 9 0 7}$ \\
$\mathbf{( 1 )}$ & $\mathbf{- 5 , 2 5 0 0}$ & $\mathbf{0 , 2 3 2 3 3}$ & $\mathbf{0 , 0 0 0 0 2 3}$ & $\mathbf{- 2 , 6 2 5 0}$ & $\mathbf{0 , 1 1 6 1 6}$ \\
$(\mathbf{2})$ & $\mathbf{- 4 , 7 5 0 0}$ & $\mathbf{0 , 2 3 2 3 3}$ & $\mathbf{0 , 0 0 0 0 3 4}$ & $\mathbf{- 2 , 3 7 5 0}$ & $\mathbf{0 , 1 1 6 1 6}$ \\
$\mathbf{3})$ & $\mathbf{- 2 , 2 5 0 0}$ & $\mathbf{0 , 2 3 2 3 3}$ & $\mathbf{0 , 0 0 0 6 3 6}$ & $\mathbf{- 1 , 1 2 5 0}$ & $\mathbf{0 , 1 1 6 1 6}$ \\
$\mathbf{1}$ x 2 & $\mathbf{- 3 , 2 5 0 0}$ & $\mathbf{0 , 2 3 2 3 3}$ & $\mathbf{0 , 0 0 0 1 5 1}$ & $\mathbf{- 1 , 6 2 5 0}$ & $\mathbf{0 , 1 1 6 1 6}$ \\
1 x 3 & 0,2500 & 0,23233 & 0,342477 & 0,1250 & 0,11616 \\
2 x 3 & $-0,2500$ & 0,23233 & 0,342477 & $-0,1250$ & 0,11616 \\
\hline
\end{tabular}

$\mathrm{R}^{2}=0,99673$. I- intercepto; 1- Velocidade do ar $(\mathrm{m} / \mathrm{s}) ; 2$ - Área de secagem $\left(\mathrm{cm}^{2}\right)$; 3- Agitação $(\mathrm{h}$ $\left.{ }^{1}\right)$. Fonte: Autor.

Figura 2 - Gráfico de Pareto.

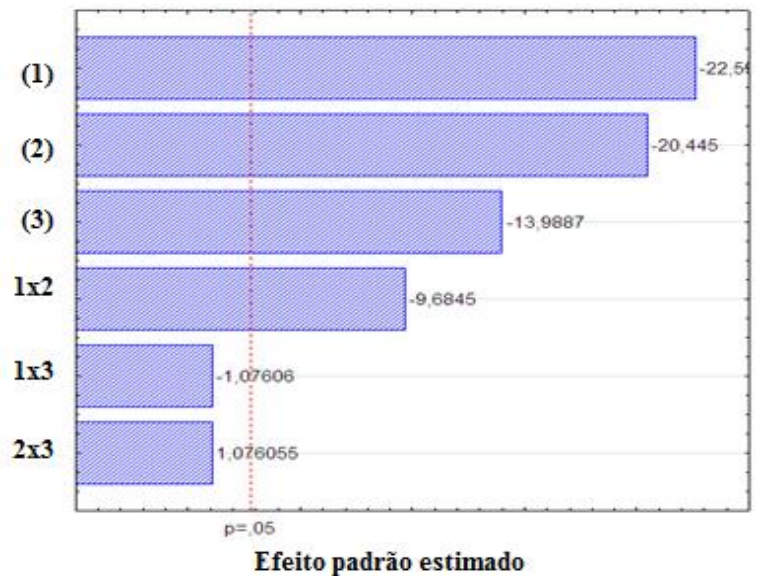

Fonte: Autor.

Os valores negativos dos três efeitos na Tabela 4 mostram um comportamento que já era esperado, o tempo de secagem diminui à medida que esses fatores crescem.

$\mathrm{O}$ fator que mais influencia no tempo de secagem, de acordo com o planejamento experimental proposto, é a velocidade do ar. A constante renovação do ar dentro da câmara evita ocorra a sua saturação, evitando a diminuição do gradiente de umidade. Assim não ocorre diminuição na taxa de transferência de massa.

$\mathrm{O}$ segundo fator significativo foi a superfície de secagem que também está relacionado ao volume do lodo. Esse resultado pode ser explicado pelo fato de que a transferência de massa ocorre pelo contato entre a superfície do lodo e o ar. Quanto maior for esta superfície de contato, maior será a transferência de massa.

O terceiro fator significativo foi a agitação. Apesar de a agitação ter se mostrado o fator menos significativo, ela é uma característica importante no desenvolvimento do projeto do protótipo. Sendo o espaço uma possível limitação para a operação de secagem, a agitação durante a desidratação do lodo se mostra uma alternativa interessante já que, de certa maneira, ela aumenta a superfície de transferência de massa quando promove a movimentação do lodo.

Na Figura 3a, 3b e 3c são apresentados resultados das superfícies de resposta. Pela análise destes gráficos, pode-se observar a interação desses fatores aos pares e determinar o tempo ótimo de secagem (dentro das condições testadas) representado pela região verde, onde são encontradas as melhores condições de secagem. Dessa maneira, as regiões vermelhas nos gráficos representam as condições menos favoráveis à secagem e, consequentemente, que demoram mais tempo para atingir o equilíbrio.

Figura 3. Superfície de resposta para o tempo de secagem com a interação: a) da superfície de secagem e velocidade do ar; b) da agitação e velocidade do ar; c) da agitação e superfície de secagem.

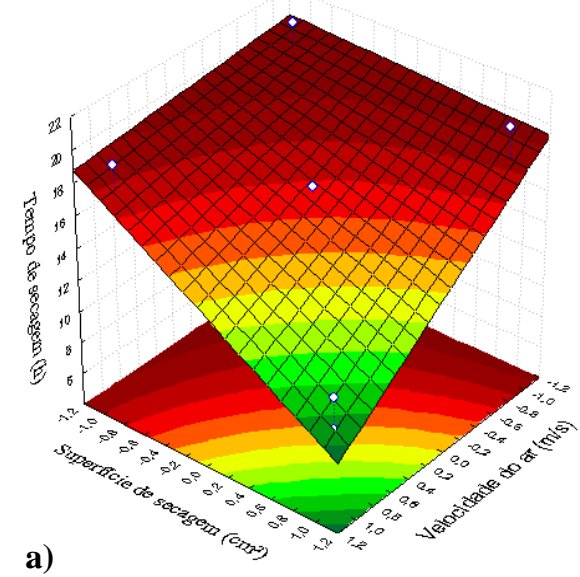




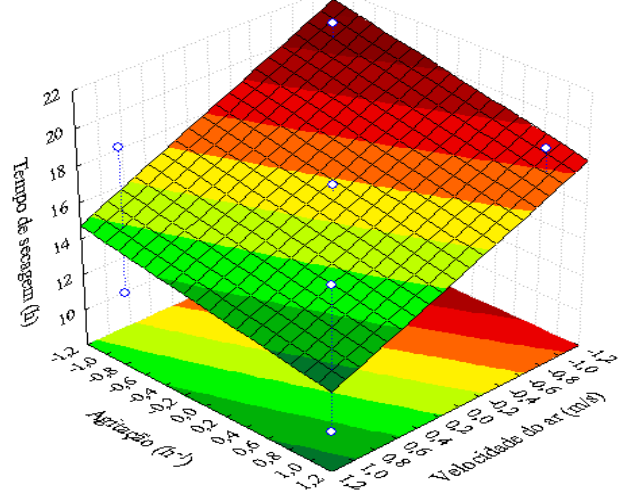

b)

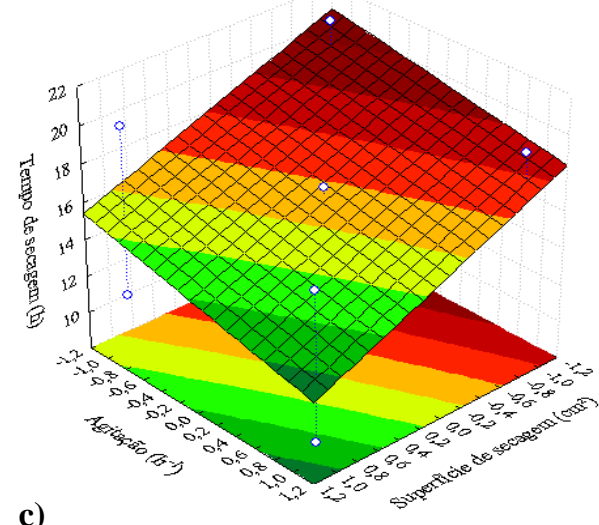

c)

Fonte: Autor.

$\mathrm{Na}$ Figura 4 é apresentado o adimensional da umidade em função do tempo.

Figura 4- Adimensional de umidade em função do tempo de secagem.

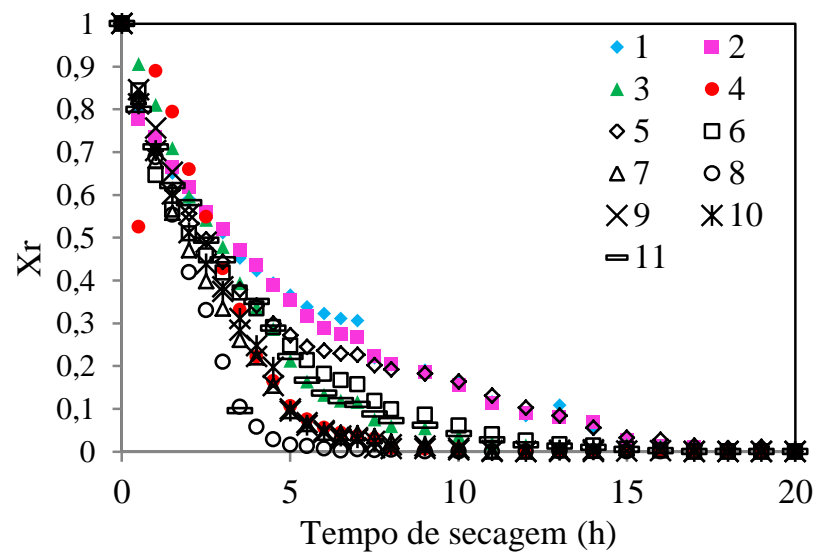

Fonte: Autor.
No início da secagem, as amostras apresentaram grandes e similares variações massa. Porém, depois de aproximadamente 4 horas as amostras passaram a apresentar algumas diferenças no comportamento.

No intervalo entre 3 e 5 horas, a amostra 8 já apresentava maior perda de massa, diferentemente das amostras 1 e cuja variação de massa foi mais lenta. As outras amostras tiveram comportamentos intermediários às amostras 1 e 8 , dependendo das condições a que estavam submetidas. Com 9 horas de secagem a amostra 8 atingiu o equilíbrio.

Entre 5 e 10 horas de secagem as amostras (com exceção da 8) continuaram apresentando variações de massa significativas. Porém, depois deste intervalo, as variações diminuíram até que fosse atingido o equilíbrio.

Na Figura 5 são mostradas as taxas de secagem em função do teor de umidade em base seca.

Figura 5 - Taxa de secagem.

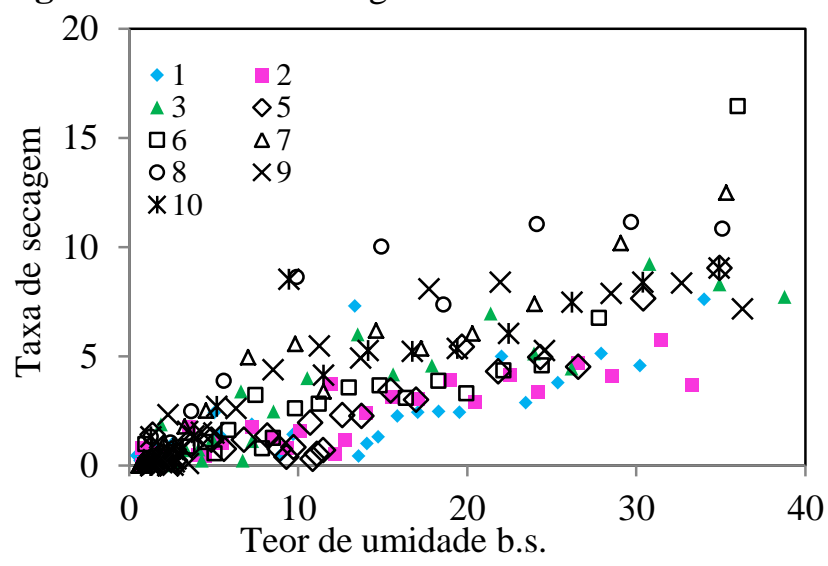

Fonte: Autor.

Na Figura 5 nota-se a ausência das quatro etapas principais de secagem caracterizadas por Deng et al. (2009) e Vaxelaire et al. (2004). Este fato pode ser explicado devido às variaçõeas das condições climáticos durante a secagem das amostras.

Porém, pode-se notar que, no começo da secagem, quando o teor de umidade em 
base seca das amostras são aproximadamente 40, as taxas de secagem são maiores, e no decorrer do processo, com a diminuição do teor de umidade, as taxas diminuem e passam a apresentar pouca variação, tendo um comportamento praticamente constante.

Nos gráficos das Figuras 6 e 7 são mostradas as variações das temperaturas de bulbo seco e bulbo úmido e umidade relativa do ar durante a secagem.

Figura 6 - Temperaturas de bulbo seco e bulbo úmido durante a secagem.

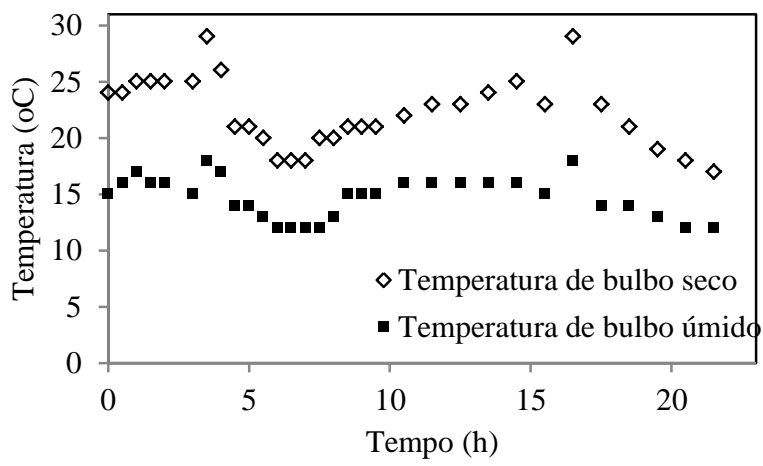

Figura 7 - Umidade relativa do ar durante a secagem.

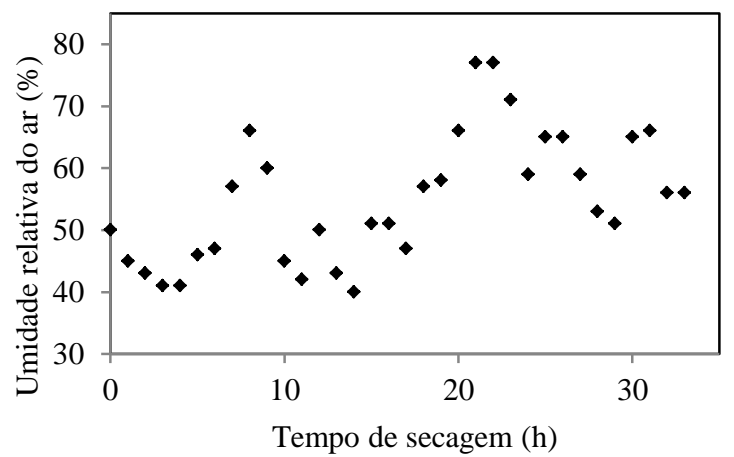

Fonte: Autor.

As Figuras mostram picos de temperatura e menores valores de umidade relativa do ar em horários perto do meio dia e temperaturas mais baixas e maiores valores de umidade relativa do ar no final da tarde e começo da manhã.

$\mathrm{Na}$ Tabela 5 são mostrados os coeficientes de correlação obtidos nos ajustes dos modelos matemáticos para cada amostra.

Fonte: Autor.

Tabela 5 - Coeficientes de correlação dos modelos ajustados.

\begin{tabular}{rllllllllllll}
\hline & \multicolumn{10}{c}{ Amostra } \\
\hline & $\mathbf{1}$ & $\mathbf{2}$ & $\mathbf{3}$ & $\mathbf{4}$ & $\mathbf{5}$ & $\mathbf{6}$ & $\mathbf{7}$ & $\mathbf{8}$ & $\mathbf{9}$ & $\mathbf{1 0}$ & $\mathbf{1 1}$ \\
\cline { 2 - 13 } $\mathbf{1}$ & 0,9861 & 0,9911 & 0,9944 & 0,8404 & 0,9847 & 0,9938 & 0,9971 & 0,9866 & 0,9888 & 0,9931 & 0,9818 \\
$\mathbf{2}$ & 0,9929 & 0,9957 & 0,9961 & 0,9555 & 0,9906 & 0,9958 & 0,9973 & 0,9886 & 0,9905 & 0,9934 & 0,9819 \\
$\mathbf{3}$ & 0,9929 & 0,9957 & 0,9961 & 0,9566 & 0,9906 & 0,9982 & 0,9973 & 0,9886 & 0,9974 & 0,9934 & 0,982 \\
$\mathbf{4}$ & 0,9933 & 0,9961 & 0,9966 & 0,9556 & 0,9921 & 0,9958 & 0,9978 & 0,9927 & 0,9925 & 0,9947 & 0,982 \\
\hline
\end{tabular}

${ }^{1}$ Lewis, (1921); ${ }^{2}$ Henderson e Pabis (1961); ${ }^{3}$ Henderson (1974); ${ }^{4}$ Logaritmico. Fonte: Autor.

Analisando os resultados da Tabela 5 em relação ao coeficiente de correlação notase que os melhores ajustes foram obtidos para a amostra 6 e 7. Porém, de maneira geral, para todas as amostras os modelos se adequaram satisfatoriamente. $\mathrm{O}$ ajuste que apresentou menor coeficiente de correlação foi obtido pelo modelo de Lewis na amostra 4. O modelo Logarítmico apresentou pequena superioridade em relação aos demais modelos matemáticos.
Devido ao grande número de amostras e espaço limitado optou-se por utilizar apenas uma amostra para representar os resultados preditos pelos modelos. Foi utilizada como amostra representativa a amostra 7 que estava submetida às condições de velocidade do ar de $0 \mathrm{~m} / \mathrm{s}$, superfície de secagem de $240 \mathrm{~cm}^{2}$ e agitação a cada 15 minutos (4 vezes por hora). Esses resultados estão apresentados na Figura 8.

Observando a Figura nota-se uma pequena discrepância entre as estimativas 
feitas pelos modelos e os resultados experimentais no intervalo entre 5 e 10 horas de secagem. Porém, de uma maneira geral, houve uma boa concordância entre valores observados e preditos.

Figura 8 - Dados experimentais e preditos para a amostra 7.

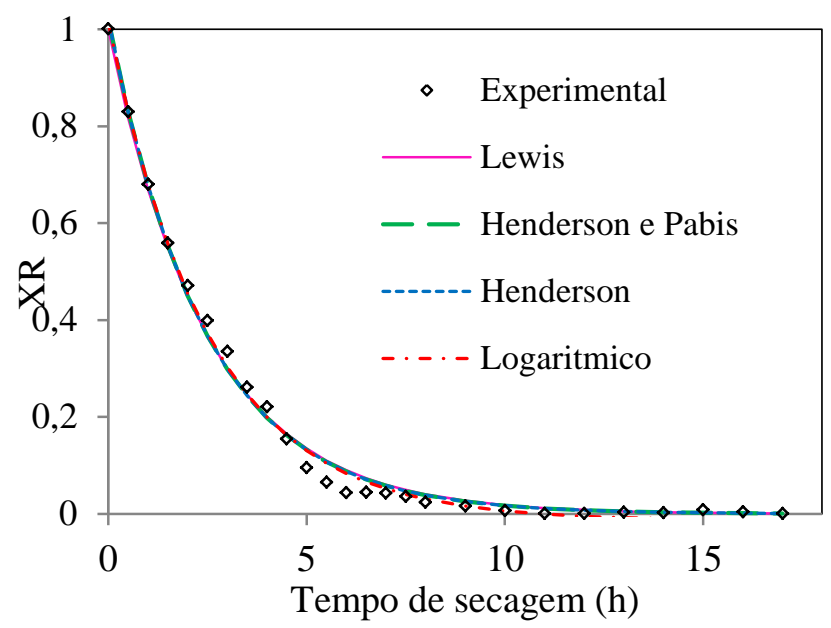

Fonte: Autor.

$\mathrm{Na}$ Tabela 6 são mostrados os parâmetros dos modelos ajustados à amostra 7.

Tabela 6 - Parâmetros dos modelos ajustados para a amostra 7.

\begin{tabular}{ll}
\hline Modelo & Parâmetros \\
\hline Lewis (1921) & $\mathrm{k}=0,400858$ \\
Henderson e Pabis (1961) & $\mathrm{a}=1,020851$ \\
& $\mathrm{k}=0,408810$ \\
Henderson (1974) & $\mathrm{a}=0,504780$ \\
& $\mathrm{~b}=0,516071$ \\
& $\mathrm{k}_{1}=0,408809$ \\
& $\mathrm{k}_{2}=0,408812$ \\
Logaritmico & $\mathrm{a}=1,028679$ \\
& $\mathrm{c}=-0,01412$ \\
& $\mathrm{k}=0,392010$ \\
& \\
\hline
\end{tabular}

Fonte: Autor.

De maneira geral, os modelos apresentaram bons ajustes aos dados experimentais.
Segundo Barros Neto et al. (1995), a análise estatística do teste $\mathrm{F}$ pode ser utilizada para determinar se o modelo é preditivo, ou seja, se ele pode ser utilizado para fins de predição da variável estudada. Segundo os autores, para que o modelo proposto seja útil para fins preditivos, $\mathrm{o}$ valor de $\mathrm{F}_{\text {calculado }}$ (Quadrado do erro médio da regressão/quadrado do erro médio do resíduo) deve ser no mínimo quatro a cinco vezes o valor de $\mathrm{F}_{\text {tabelado. Neste caso, em todos os }}$ modelos este critério foi atingido, confirmando que os modelos são preditivos.

\section{NOMENCLATURA}

$\mathrm{X}_{1}$ - Velocidade do ar

$\mathrm{X}_{2}-$ Superfície de secagem $\left(\mathrm{cm}^{2}\right)$

$\mathrm{X}_{3}$ - Agitação (agitação/hora)

$\mathrm{t}$ - Tempo de secagem (h).

$\mathrm{m}$ - Massa (g)

$\mathrm{m}_{\mathrm{i}}$ - Massa inicial $(\mathrm{g})$

$\mathrm{m}_{\mathrm{s}}$ - Massa seca $(\mathrm{g})$

$\mathrm{t}$ - Tempo (min)

$\mathrm{T}$ - Temperatura (oC)

$\mathrm{v}$-Velocidade do ar $(\mathrm{m} / \mathrm{s})$

$\bar{X}$ - Teor de umidade em base seca

$\mathrm{X}_{0}$ - Teor de umidade inicial em base seca

$\mathrm{X}_{\mathrm{eq}}$ - Teor de umidade em equilíbrio em base seca

$\mathrm{X}_{\mathrm{R}}$ - Adimencional de umidade (g.g-1)

$\mathrm{N}$ - Taxa de secagem $\left(\mathrm{g}_{\text {água }} \cdot \mathrm{g}_{\mathrm{ss}}{ }^{-1} \cdot \mathrm{h}^{-1} \cdot \mathrm{cm}^{-2}\right)$

A - Área $\left(\mathrm{cm}^{2}\right)$

\section{CONCLUSÕES}

O lodo apresentou um teor de umidade alto de $95,6 \%$, se enquadrando na classificação de lodo fluido ou diluído. Esse resultado reforçou ainda mais a necessidade de um processo de desidratação para melhorar sua utilização e também facilitar seu transporte.

Os resultados mostraram condições de secagem mais favoráveis às maiores velocidade do ar, quantidade de agitação e área da superfície. 
Os modelos matemáticas apresentaram um bom ajuste aos dados e permitem prever o comportamento do lodo durante a secagem, mesmo neste tipo de processo, em que não se tem o controle de todas as variáveis, devido às variações climáticas. Dentre os modelos utilizados, o que apresentou melhor ajuste foi o modelo Logarítmico para a amostra 7.

\section{REFERÊNCIAS}

ANDREOLI, C. V.; FERREIRA, A. C.; TELES, C. R.; CHERUBINI, C.; BERNET, P. M.; FAVARIN, F.; CASTRO, L. R. de. Avaliação da eficiência do uso de estufa plástica, revolvimento de lodo e injeção de calor na secagem e desinfecção de lodo anaeróbio em leito de secagem. In: Ix Simpósio Luso Brasileiro De Engenharia Sanitária E Ambiental. Anais..Porto Seguro, 2000.

BARROS NETO, B., SCARMÍNIO, I.S., BRUNS, R.E. Planejamento e otimização de experimentos. Campinas: Editora da UNICAMP, 1995.

BENNAMOUN L. Solar drying of wastewater sludge: A review. Renewable and Sustainable Energy Reviews, v. 16, p.1061- 1073, 2012.

BOUALAGUI, H., HAOUARI, O., TOUHAMI, Y., BEN-CHEIKH, R., MAROUANI, L., HAMDI, M. Effect of temperature on the performance of an anerobic tubular reactor treating fruit and vegetable waste. Process Biochemistry, v. 39, p. 2143-2148, 2004.

DE BAERE, L. Anaerobic digestion of solid waste: state-of-the-art. Water Science \& Technology, v. 41: p. 283-290, 2000.

DENG W. Y.; YAN J. H.; LI, X. D.; WANG F.; LU S. Y.; CHI Y., CEN, K. Measurement and simulation of the contact drying of sewage sludge in a Nara-type paddle dryer. Chemical Engineering Science, v. 64 p. 5117-5124, 2009.

FILHO, P.M. Reciclagem da matéria orgânica através da vermicompostagem. In: Metodologia e técnicas de minimização, reciclagem e reutilização de resíduos sólidos urbanos.Anais...Ed. ABES, 1999. Rio de Janeiro/RJ. p. 31.

FOUST, A. S.; WENZEL, L. A.; CLUMP, C. W.; MAUS, L.; ANDERSEN, L. B. Princípios das Operações Unitárias. Editora Guanabara, 2a edição. Rio de Janeiro, 1982.

HENDERSON, S. M. Progress in developing the thin layer drying equation. Trans. Am.

Soc. Agr. Eng., v. 17, p. 1167-8, 1974,

HENDERSON, S. M.; PABIS, S. Grain drying theory. I. Temperature effects on drying coefficient. J. Agric. Eng. Res., v.6, p. 169-74, 1961.

KIEHL, E. J., 1985, Fertilizantes Orgânicos. São Paulo: Editora Agronômica - CERES.

LAUFER, A. Avaliação de processo alternativo de biodigestão para Tratamento de resíduos sólidos orgânicos domésticos, 2010. Dissertação (Mestrado em Engenharia Química) - Universidade Estadual do Oeste do Paraná, Toledo.

LEWIS, W. K. The drying of solid materials. J. Ind. Eng., v. 5, p. 427-33, 1921

McCABE, W. L., SMITH, J., HARRIOT, P. Unit Operations of Chemical Engineering, McGraw-Hill, Fifth Edition, 1993.

MOREJON, C. F. M.; LIMA, J. F de; ROCHA JR.; W. F., DALLA POSSA R. New 
model of municipal solid waste management.

Int. J. Environment and Sustainable Development, v. 11, n. 3, 2012.

STATISTICA. Data Analysis Software

System, v.8.0, Stat-Soft, Inc., USA. 2008. www.statsoft.com.

VAXELAIRE J, CÉZAC P. Moisture distribution in activated sludges: a review. Water Research, v. 38 p. 2215-230, 2004.

\section{AGRADECIMENTOS}

Ao CNPq pelo apoio financeiro. 